\title{
Anabolic-androgenic steroid use among bodybuilders in Erbil city
}

\section{Abstract}

Background and objective: Anabolic-androgenic steroids are synthetic testosterone derivatives with a longer duration of action than physiological androgens. They are abused by bodybuilders because of their potential to enhance muscle strength. Serious medical and psychological complications may be associated with their non-medical use. This study aimed to determine the prevalence of anabolic androgenic steroids among bodybuilders and their awareness of health-related risks.

Methods: A cross-sectional study was carried out from the 1st of January 2019 to the end of July 2019 in 18 randomly selected gym centers in Erbil city, Iraq using stratified random sampling. A self-administered questionnaire was distributed to 400 bodybuilders to assess the prevalence and knowledge of using Anabolic-androgenic steroids.

Results: The study showed a high prevalence of Anabolic-androgenic steroid consumption $(26.3 \%)$ among gym users in Erbil city. Anabolic-androgenic steroid use was significantly higher among participants with a longer duration of bodybuilding practice $\geq 4$ years $(P=0.001)$. Anabolic-androgenic steroid abuse was significantly associated with drinking alcohol, smoking cigarettes, and using growth hormones. Trainers were the commonest source of recommendation.

Conclusion: The prevalence of anabolic androgenic steroids abuse is high among bodybuilders in Erbil city. Public health awareness is essential and may help avoid the propagation of the problem.

Keywords: Anabolic steroids; Gym users; Bodybuilders; Knowledge, Erbil.

\section{Introduction}

Anabolic-androgenic steroids (AAS) are synthetic derivatives of testosterone, which were appeared in the late 1930s. More than 1,000 testosterone derivatives have been formulated. Testosterone has a short half-life. To overcome this rapid metabolism, many artificial AAS have been synthesized. They have been designed to have longer half-lives. The United States Food and Drug Administration approved a variety of AAS to treat wasting syndrome in human immunodeficiency virus infection, hypogonadism, renal and bone marrow failure, cancer-related cachexia, and endometriosis. It may also play a role in immobilized patients. Administering higher than normal doses of AAS, especially if combined with resistance exercise, may increase muscle size and strength, whereas fat mass and endurance fulfillment were discovered to be unaffected. ${ }^{1-5}$

The first reports of AAS occurred during the 1954 world weightlifting championships. The use of these drugs expanded quickly through the 1960s and grew in popularity among athletes in various competitions. Nowadays, AAS is used worldwide by millions of men, many of them having no athletic aspiration, hoping to improve their physical strength and appearance. With higher levels of use occurring among recreational bodybuilders and those who use AAS for either occupational or aesthetic purposes.

${ }^{1}$ Family Medicine Residency Program, Kurdistan Board of Medical Specialties, Erbil, I raq.

2 Department of Community Medicine, College of Medicine, Hawler Medical University, Erbil, I raq.

* Correspondence: m.dremezan@gmail.com 
The prevalence of use ranges from $9.3 \%$ to $79.6 \% .^{3-9}$

Studies showed that using AAS in such high doses irreversibly exerts effects on many organs, elevating blood pressure, serum lipoproteins, and blood sugar. ${ }^{1}$ Acute coronary syndrome and fatal ventricular arrhythmias. Hepatocellular carcinoma and adenoma. Proteinuria and focal segmental glomerulosclerosis. ${ }^{2,7,10}$ Oligospermia, infertility, libido changes, and decrease the size of testicles. Behavioral changes, depression, mood swings, and mania. ${ }^{1,7,11}$

Acne and male pattern baldness are the most frequently reported harmful effects. Using AAS before puberty has been known to cause short stature, also increase the risk of tendon rupture and intramuscular abscess. AAS abusers tend to abuse other drugs like tobacco, alcohol, and different types of performance-enhancing agents like morphine, ecstasy, hashish, marijuana, and cocaine. .,8,9 $^{-1}$

Studies have found that AAS users have substantial awareness about the potential hazards of AAS usage. Interestingly, higher education is not necessarily a protective factor for AAS use. ${ }^{6-8,12}$ Couches are an important factor for abusing AAS because they are the main source of recommendations since they want their trainees to achieve rapid results. $6,12,13$

Recently, the Kurdistan region witnessed a fastest-growing of bodybuilder centers. However, they are not under health authority instructions. Therefore, the present study aimed to determine the prevalence of AAS among bodybuilders and their perception of health-related risks.

\section{Methods}

\section{Study design, setting, and time}

A cross-sectional survey study was carried out in eighteen gym centers in different parts of Erbil city using stratified random sampling from the 1st of January 2019 to the end of July 2019. The centers were chosen in such a way to cover all geographical parts of the city.

\section{Study population:}

The study was conducted on 400 gym users who agreed to participate in the study. Those who joined these centers for less than six weeks were excluded from the study. The sample size was calculated by formula, where the level of confidence (95\%), p (expected prevalence) $=20 \%, d$ (precision) $=5 \%$, the total population is one million, the sample size was supposed to be 400 subjects. ${ }^{14}$

\section{Data collection:}

A self-administered questionnaire was utilized and completed by all participants. The questionnaire was designed after reviewing several studies conducted in the same domain. ${ }^{7,15}$ The final version of the questionnaire involved approximately 52 multiple-choice questions related to demography, socioeconomic status, AAS abuse, attitude, and assessment of their knowledge regarding harmful effects, agree/disagree knowledge quiz, perception, and opinion about AAS, questions on motivations for steroid usage, patterns of steroid use, sources of steroid-related knowledge and accounts of health harms. Socioeconomic status estimated according to the index for health research in Iraq. ${ }^{16}$

\section{Data analysis:}

Data entry was done, and statistical analysis was conducted using the statistical package for the social sciences (SPSS, version 25). The data were presented as frequencies and percentages. The level of significance in this study was $\leq 0.05 \%$. A Chi-square test and Fisher's exact test were used to assess the association between categorical variables.

\section{Ethical consideration:}

All participants were interviewed and informed of the study objective, then recruited after obtaining verbal informed consent. The study was approved by the research protocol ethics committee of the Kurdistan Board of Medical Specialties. 


\section{Results}

A total of 400 bodybuilders participated in the study. The mean age of the participants was $27.8 \pm 7.8$ years, ranging from 16 to 60 years. Regarding marital status, $55 \%$ of the participants were single and $45 \%$ were married. Regarding socioeconomic status, the majority of participants belong to intermediate socioeconomic status (53.25\%), as shown in Table 1.

The lifetime prevalence of using AAS among bodybuilders was $26.3 \%$, the mean duration of use \pm SD was $4 \pm 4.4$ months, as shown in Table 2.

Table 1 Socio-demographic characteristic of AAS users in Erbil city $(n=400)$

\begin{tabular}{llcccc}
\hline Characteristic & & $\begin{array}{c}\text { Never used AAS } \\
\text { No. (\%) }\end{array}$ & $\begin{array}{c}\text { Have used AAS } \\
\text { No. (\%) }\end{array}$ & $\begin{array}{c}\text { Total } \\
\text { No. (\%) }\end{array}$ & P value \\
\hline Age (years) & $\leq 20$ & $57(19.3)$ & $14(13.3)$ & $71(17.75)$ & $0.135^{*}$ \\
& $21-30$ & $157(53.2)$ & $61(58.1)$ & $218(54.5)$ & \\
& $31-40$ & $54(18.3)$ & $26(24.8)$ & $80(20)$ & \\
& $41-50$ & $21(7.1)$ & $4(3.8)$ & $25(6.25)$ & \\
Marital status & Single & $167(56.6)$ & $53(53)$ & $220(55)$ & $0.352^{*}$ \\
& Married & $128(43.4)$ & $52(49.5)$ & $180(45)$ & \\
Socio-economic & Low & $118(40.0)$ & $36(36.0)$ & $154(38.5)$ & $0.583^{*}$ \\
status & Intermediate & $153(51.9)$ & $60(57.1)$ & $213(53.25)$ & \\
& High & $24(8.1)$ & $9(8.6)$ & $33(8.25)$ & \\
Total & & $295(100)$ & $105(100)$ & $400(100)$ & \\
\hline
\end{tabular}

* Chi-square

AAA: Anabolic-androgenic steroids

Table 2 Frequency and lifetime prevalence of using AAS

\begin{tabular}{lcc}
\hline Frequency of use & No. & (\%) $\mathbf{n}=\mathbf{4 0 0}$ \\
\hline Never & 295 & $(73.75)$ \\
Experimented & 40 & $(10.0)$ \\
Previously & 47 & $(11.75)$ \\
Current use & 18 & $(4.5)$ \\
Total & 400 & $(100.0)$ \\
The lifetime prevalence of using AAS & 105 & $(26.3)$ \\
\hline
\end{tabular}

AAA: Anabolic-androgenic steroids 
Most of the participants in the AAS nonuser group have practiced bodybuilding exercises for $1-2.9$ years $(37.9 \%)$, while in the AAS user group, most of them have practiced bodybuilding exercise $\geq 4$ years. The majority of participants in AAS user and AAS non-user exercise 5 days per week $(82.9 \%, 74.6 \%$, respectively), as shown in Table 3.

The prevalence of cigarette smoking was $25.7 \%$ among AAS abusers, while only $5.7 \%$ drink alcohol, and $25.7 \%$ use growth hormone. While in AAS non-users, $11.5 \%$ and $15.1 \%$ of them were smoking cigarettes and use stimulants, respectively, as shown in Table 4.

Table 3 Training habits by the use of the AAS.

\begin{tabular}{llccc}
\hline & & $\begin{array}{c}\text { Never used AAS } \\
\text { No. (\%) }\end{array}$ & $\begin{array}{c}\text { Have used AAS } \\
\text { No. (\%) }\end{array}$ & $P$ value \\
\hline Time practicing & $<1$ & $61(20.7)$ & $11(10.5)$ & $0.001^{*}$ \\
bodybuilding & $1-1.9$ & $112(37.9)$ & $21(20)$ & \\
(years) & $2-2.9$ & $51(17.3)$ & $17(16.2)$ & \\
& $3-3.9$ & $35(11.9)$ & $16(15.2)$ & \\
Dayl Week & $\geq 4$ & $36(12.2)$ & $40(38.1)$ & \\
& $2 \times$ days & $2(0.7)$ & $1(1.0)$ & $0.113^{* *}$ \\
& $3 \times$ days & $22(7.5)$ & $2(1.9)$ & \\
Time spent per & $4 \times$ days & $51(17.3)$ & $15(14.3)$ & \\
training session & 2 ho days & $220(74.6)$ & $87(82.9)$ & \\
& 1 hour & $27(9.2)$ & $3(2.9)$ & $0.128^{* *}$ \\
& 2 hours & $180(61.0)$ & $66(62.9)$ & \\
Total & 3 hours & $25(28.8)$ & $34(32.4)$ & \\
& $\geq 5$ hours & $2(0.7)$ & $2(1.9)$ & \\
& & $1(0.3)$ & $0(0.0)$ & \\
\hline
\end{tabular}

* Chi Square ${ }^{* *}$ Fisher's exact test AAA: Anabolic-androgenic steroids

Table 4 Using other substances along with ASS abuse

\begin{tabular}{lccc}
\hline Substance & $\begin{array}{c}\text { Never used AAS } \mathbf{n = 2 9 5} \\
(\%)\end{array}$ & $\begin{array}{c}\text { Have used AAS } \mathbf{n = 1 0 5} \\
(\%)\end{array}$ & $\boldsymbol{P}$ value \\
\hline Stimulant & $15(5.08)$ & $9(8.57)$ & $0.231^{*}$ \\
Insulin & $1(0.33)$ & $5(4.76)$ & $0.006^{*}$ \\
Growth hormone & $6(2.03)$ & $27(25.71)$ & $0.001^{*}$ \\
Erythropoietin & $0(0.0)$ & $1(0.95)$ & $0.262^{*}$ \\
Alcohol & $5(1.69)$ & $6(5.71)$ & $0.410^{*}$ \\
Cigarette smoking & $34(11.52)$ & $27(25.71)$ & $0.001^{*}$ \\
Water pipe smoking & $42(14.23)$ & $18(17.6)$ & $0.525^{*}$ \\
Total (used substances) & 103 & 93 & \\
Total (not used substances) & 192 & 12 & \\
Total & $295(100)$ & $105(100)$ & \\
\hline
\end{tabular}

*Fisher's exact test AAA: Anabolic-androgenic steroids 
Anabolic-androgenic steroid use among bodybuilders ... Z Zanco J. Med. Sci., Vol. 25, No. (3), December, 2021 https:/ / doi.org/ 10.15218/ zjms.2021.032

Figure 1 shows the knowledge assessment of participants in regards to the health hazards of AAS abuse. The participants were asked to check whether they agreed or disagreed with the statements. Of the total sample, $48 \%$ agree that using AAS is harmful, causes kidney damage $(44.75 \%)$, sexual dysfunction (38.25), and heart disease (28.75\%), and is beneficial $(25.25 \%)$.

The parenteral route was the main route of administration $(41.7 \%)$. Trainers were the most common person who administered injections, and they were the main source of recommendations $(50 \%$ and $78.1 \%$, respectively). The main reason for using AAS was to increase muscle mass $(84.5 \%)$. Most of the participants recalled that the acquisition of AAS drugs is easily available (75.8\%). Sixty-five percent of AAS users have received drugs randomly during the competitive season and off-season, as shown in Table 5.

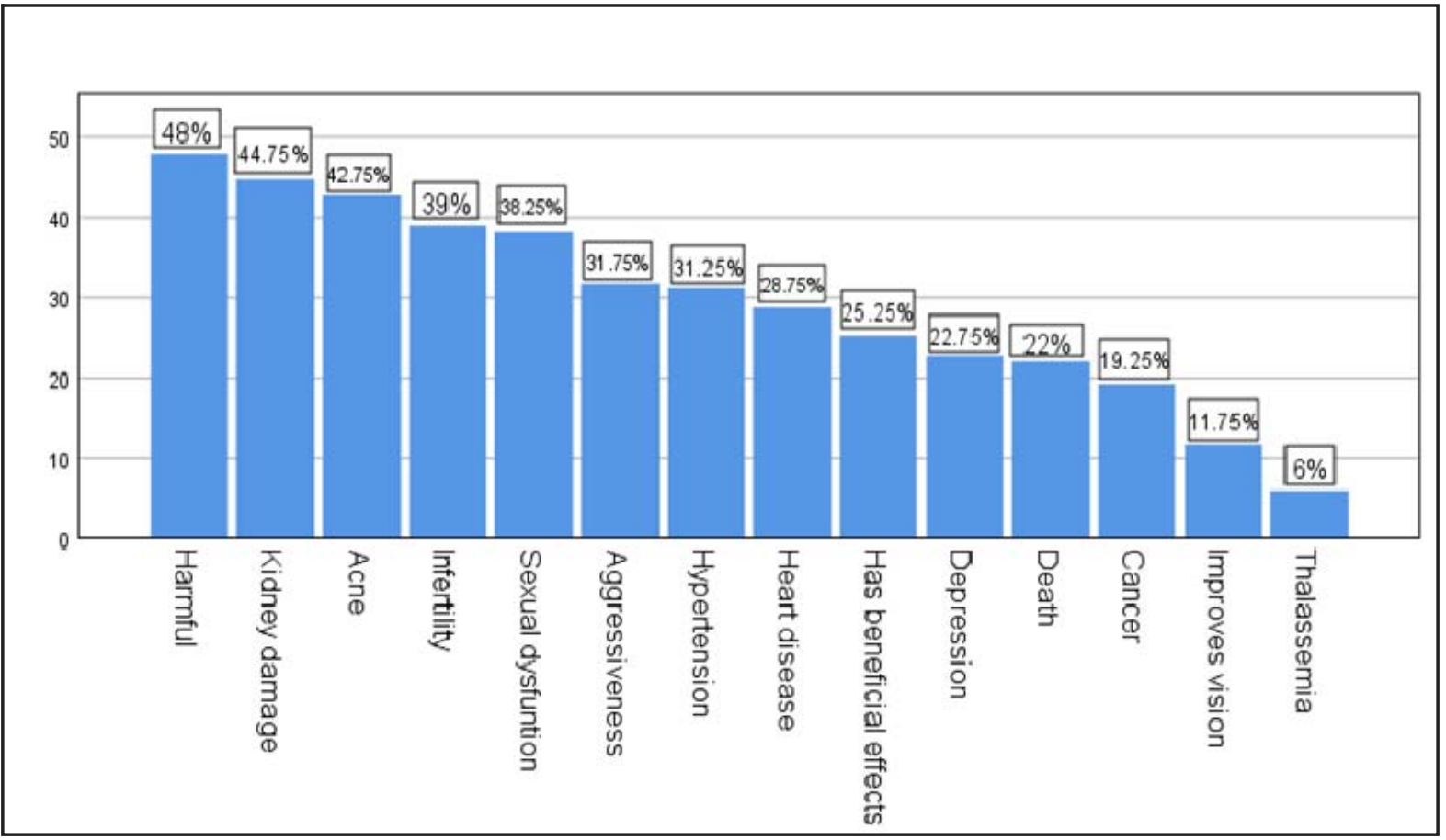

Figure 1 Participants agreement percentage in regards harmful effects 
Anabolic-androgenic steroid use among bodybuilders ... Zanco J. Med. Sci., Vol. 25, No. (3), December, 2021 https:/ / doi.org/ 10.15218/ zjms.2021.032

Table 5 Frequency of AAS practice

\begin{tabular}{|c|c|c|c|}
\hline Variable & & No. & (\%) \\
\hline \multirow[t]{4}{*}{ Route of Administration } & Parenteral & 43 & $(41.0)$ \\
\hline & Oral & 22 & $(21.0)$ \\
\hline & Both & 40 & $(38.0)$ \\
\hline & Total & 105 & $(100)$ \\
\hline \multirow[t]{7}{*}{ Who administer it for you } & Trainer & 45 & $(42.9)$ \\
\hline & Medic & 30 & $(28.6)$ \\
\hline & Teammate & 3 & $(2.9)$ \\
\hline & Friends & 2 & $(1.9)$ \\
\hline & Myself & 24 & $(22.9)$ \\
\hline & Other & 1 & $(1.1)$ \\
\hline & Total & 105 & $(100)$ \\
\hline \multirow[t]{7}{*}{ The source of AAS recommendations } & Trainers & 82 & $(78.1)$ \\
\hline & Friends & 9 & $(8.6)$ \\
\hline & TV & 1 & $(1.0)$ \\
\hline & Internet & 6 & $(5.6)$ \\
\hline & Medic & 5 & $(4.8)$ \\
\hline & Others & 2 & $(1.9)$ \\
\hline & Total & 105 & $(100)$ \\
\hline \multirow[t]{6}{*}{ The main reason for using AAS } & Boost health & 9 & $(5.96)$ \\
\hline & Muscle mass increase & 87 & $(57.61)$ \\
\hline & Weight gain & 20 & $(13.24)$ \\
\hline & Muscle power increase & 24 & $(15.91)$ \\
\hline & Muscle endurance increase & 11 & $(7.28)$ \\
\hline & Total & 151 & $(100)$ \\
\hline \multirow[t]{4}{*}{ Availability of AAS drugs } & Readily available & 303 & $(75.8)$ \\
\hline & Somewhat difficult & 67 & $(16.7)$ \\
\hline & Difficult & 30 & $(7.5)$ \\
\hline & Total & 400 & $(100)$ \\
\hline \multirow[t]{3}{*}{ Timing of using AAS } & Competitive season & 36 & $(34.28)$ \\
\hline & Competitive and offseason & 69 & $(65.71)$ \\
\hline & Total & 105 & $(100)$ \\
\hline
\end{tabular}

AAA: Anabolic-androgenic steroids 


\section{Discussion}

After reviewing the literature, no study has been conducted to test the prevalence and characteristics of AAS users among bodybuilders in Erbil city, Iraq. Health care professionals should understand and be prepared to educate about AAS that is widely abused by athletes.

Understanding the pattern and prevalence of AAS usage in different groups of athletes can lead to effective policy or intervention toward the target population. Furthermore, this study addresses the average age of initiation of AAS and why do most adult users initiate steroid derivatives as adolescents.

In the present study, the prevalence of using AAS among bodybuilders was $26.3 \%$, a result that is comparable with or near to other studies done in Iran Hamadan, ${ }^{12}$ Saudi Arabia, ${ }^{7}$ UAE, Al-Ain city, ${ }^{13}$ and Brazil $^{17}$ which revealed $(28.8 \%$, $31 \%, 22 \%$, and $26 \%$ respectively), and also other studies in Jazan, Saudi Arabia(31\%), ${ }^{7}$ in UAE, Al-Ain city $(22 \%),{ }^{13}$ and in Brazil (26.6\%). ${ }^{17}$ However, our result was lower compared to Baghdad city $44.8 \%,{ }^{15}$ Kuwait $35 \%,{ }^{8}$ and Iran in Bushehr $51.7 \%{ }^{18}$ This difference might be related to the fact that bodybuilding practice is recently gaining popularity in Erbil-city, and many of the participants were cautious about disclosing true information.

There was no significant association between AAS abuse with marital status and the socioeconomic background of participants. This is also concluded in other studies such as Bushehr ${ }^{18}$ and Shiraz in Iran. ${ }^{19}$ Opposite results were found in other studies. A study in Al-Ain District in UAE found a negative association between a high level of education and AAS abuse. ${ }^{13}$ In Jazan, Saudi Arabia, the prevalence of AAS use was higher among those who received higher education. ${ }^{7} \mathrm{~A}$ significant association was found between being married and AAS abuse in Saudi Arabia. ${ }^{6}$ This is not similar in many studies because of different levels of education among participants. Trainers are the commonest person regarding the recommendation of using AAS (78.1\%). Therefore, they are a risk factor for using such hormones. The same result was seen in other studies in Saudi Arabia $^{6}$ and Iran Shiraz ${ }^{19}$ (43.3\% and $54.16 \%$, respectively). In our study, participants with a long duration of bodybuilding exercise of $\geq 4$ years have had a higher rate of using AAS (38.1\%, $P=0.001 \%)$. This result compared with other regional studies in Iran in Hamadan $^{12}$ and Shiraz ${ }^{19}(45 \%, P=0.001$ and $56.2 \%, P=0.001$, respectively).

Their tendency to use other harmful substances like cigarette smoking is higher among AAS abusers (25.7\%). In other studies, the same condition was observed in Iran in Bushehr ${ }^{18}$ and Kerman city, ${ }^{9}$ Saudi Arabia $^{6}$ (33.9\%, 44.9\%, and 39.2\%, respectively). There was a significant correlation between AAS abuse and alcohol $(5.7 \%)$. This relation was also noted in other studies in Iran in Kerman and Sweden $(56.7 \%$ and $64 \%$, respectively). In the present study, a significant correlation was found between AAS abuse and growth hormone administration $25.7 \%$. This significant relationship had also been noted in Saudi Arabia $(34.8 \%){ }^{6}$

Increasing muscle mass was the main motivation for using AAS (84.5\%), which is consistent with other studies in Iran in Bushehr, ${ }^{18}$ Shiraz, ${ }^{19}$ and Kerman city, ${ }^{9}$ (70.10\%, 75.7\%, and $78 \%$, respectively). Among participants, $75.8 \%$ clarified that the drug is easily available. This case was observed in Al-Ain city in UAE 60\%). ${ }^{13}$

Surprisingly, in the present study, multiple questions revealed that $48 \%$ agree that using AAS has a harmful effect. Participants revealed kidney damage in $44.75 \%$, sexual dysfunction in $38.25 \%$, and heart disease in $28.75 \%$. Bodybuilders were little aware of common harmful effects; this is because the majority of them are adolescents and have a low level of education. Also, similar to reports from other reviewers from Saudi Arabia in Jazan, ${ }^{7} 55.9 \%$ agreed that using AAS is 
harmful, causes sexual dysfunction (39\%), and causes hypertension $(30.5 \%)$. In UAE, in Al-Ain city, ${ }^{13} 11 \%$ agreed that using AAS causes heart disease, and $5 \%$ agreed that it causes sexual dysfunction.

In an attempt to reduce AAS abuse, evaluation parameters of choosing heroes might be changed, such as adding points from biomedical and training habits to the physical phenotype of the hero. Involving trainers in educating bodybuilders about the hazards of drugs are effective in reducing AAS consumption.

The possible limitation of our study is using a self-report questionnaire. Conducting longitudinal studies is recommended to gain more information about the harmful effects of consuming AAS.

\section{Conclusion}

The findings of this study showed that the prevalence of AAS use was high among bodybuilders in Erbil city. Some training habits and socio-demographic factors were observed to be associated with AAS misuse. In the present study, AAS use was mainly recommended by gym trainers, and the main reason for AAS misuse seems to increase muscle mass. Considering the increasing prevalence of AAS misuse, it seems that there is a need for more longitudinal studies on the benefits, possible side effects, and the impact of AAS.

\section{Funding}

None.

\section{Competing interests}

None declared.

\section{References}

1. Hartgens F. Effects of androgenic-anabolic. Sport Med. 2014; 34(November):513-54. https://doi.org/10.2165/00007256-20043408000003.

2. Achar S, Rostamian A, Narayan SM. Cardiac and metabolic effects of anabolic-androgenic steroid abuse on lipids, blood pressure, left ventricular dimensions, and rhythm. Am J Cardiol. 2010; 106(6):893-901. https://doi.org/10.1016/ j.amjcard.2010.05.013
3. Momaya A, Fawal M, Estes R. Performanceenhancing substances in sports: A review of the literature. Sport Med. 2015; 45(4):517-31. https://doi.org/10.1007/s40279-015-0308-9.

4. Sagoe D, Molde H, Andreassen CS, Torsheim T, Pallesen $S$. The global epidemiology of anabolic-androgenic steroid use: A meta-analysis and meta-regression analysis. Ann Epidemiol. 2014; 24(5):383-98. https://doi.org/10.1016/ j.annepidem.2014.01.009.

5. Christou MA, Christou PA, Markozannes G, Tsatsoulis A, Mastorakos G, Tigas S. Effects of anabolic androgenic steroids on the reproductive system of athletes and recreational users: A systematic review and meta-analysis. Sport Med. 2017; 47(9):1869-83. https://doi.org/ 10.1007/s40279-017-0709-z.

6. Althobiti S, Alqurashi N, Alotaibi A, Alharthi T, Alswat K. Prevalence, attitude, knowledge, and practice of anabolic androgenic steroid (AAS) use among gym participants. Mater Socio Medica. 2018; 30(1):49. https://doi.org/10.5455/ msm.2018.30.49-52.

7. Bahri A, Mahfouz MS, Marran NM, Dighriri YH, Alessa HS, Khwaji MO, et al. Prevalence and awareness of anabolic androgenic steroid use among male body builders in Jazan, Saudi Arabia. Trop J Pharm Res. 2017; 16(6):1425-30. https://doi.org/10.4314/tipr.v16i6.29.

8. Khullar N, Scull N, Deeny M, Hamdan E. Prevalence and predictors of anabolic-androgenic steroid use among gym users in Kuwait: A preliminary study. Int $\mathrm{J}$ Mens Health. 2016; 15(2):144-56.

9. Nakhaee MR, Pakravan F, Nakhaee N Prevalence of use of anabolic steroids by bodybuilders using three methods in a city of Iran. Addict Heal. 2016; 5(3-4):77-82.

10. Herlitz LC, Markowitz GS, Farris AB, Schwimmer JA, Stokes MB, Kunis C, et al. Development of focal segmental glomerulosclerosis after anabolic steroid abuse. J Am Soc Nephrol. 2010; 21(1):163-72. https://doi.org/10.1681/ASN. 2009040450.

11. Sharef AY, Rasoul AM. Nandrolone effects on men's semen parameters in Erbil city. Zanco J Med Sci. 2017; 21(2):1688-95. https://doi.org/10.15218/zjms.2017.021.

12. Razavi Z, Moeini B, Shafiei Y, Bazmamoun H. Prevalence of anabolic steroid use and associated factors among bodybuilders in Hamadan, western province of Iran. J Res Health Sci. 2014; 14(2):163-6.

13. Al-Falasi O, Al-Dahmani $\mathrm{K}, \mathrm{Al}$-Eisaei $\mathrm{K}$, Al-Ameri S, Al-Maskari F, Nagelkerke N, et al. Knowledge, attitude and practice of anabolic steroids use among gym users in Al-Ain district, United Arab Emirates. Open Sport Med J. 2009; 2(1):75-81. https://doi.org/10.2174/1874387000802010075.

14. Charan J, Biswas T. How to calculate sample size for different study designs in medical 
research? Indian J Psychol Med. 2013; 35(2):121. https://doi.org/10.4103/0253-7176.116232.

15. Habeeb MB, Kasim WJ, Khamees LA, Hawi MM, Nea Q. Athletes' perceptions toward substance use in Baghdad city. AJMH. 2012; 6(6):462-71. https://doi.org/10.1177/1557988312446508.

16. Omer W, Al-Hadithi T. Developing a socioeconomic index for health research in Iraq. East Mediterr Health J. 2017; 23(10):670-7. https://doi.org/10.26719/2017.23.10.670.

17. De Siqueira Nogueira FR, De Freitas Brito A, De Oliveira CVC, Vieira TI, Beniz Gouveia RL. Anabolic-androgenic steroid use among Brazilian bodybuilders. Subst Use Misuse. 2014; 49(9):1138-45. https://doi.org/10.3109/10826084.2014.912062.

18. Haerinejad MJ, Ostovar A, Farzaneh MR, Keshavarz M. The prevalence and characteristics of performance-enhancing drug use among bodybuilding athletes in the south of Iran, Bushehr. Asian J Sports Med. 2016; 7(3):e35018. https://doi.org/10.5812/asjsm.35018.

19. Fijan A, Eftekhari $\mathrm{MH}$, Dashtabi A. The prevalence of anabolic androgenic steroid misuse and its associated factors among bodybuilders in Shiraz, Iran. Int J Nutr Sci. 2018; 3(3):151-6. 